Folia Cardiologica 2021 vol. 16, no. 6, pages 416-419 DOI: 10.5603/FC.2021.0060 Copyright (C) 2021 Via Medica ISSN 2353-7752 e-ISSN 2353-7760

\title{
Cardiac pacing in vasovagal syncope in the light of the latest recommendations
}

\author{
Monika Chmielecka ${ }^{1}$, Zuzanna Myszka ${ }^{2}$, Maciej Pytka ${ }^{3}$, Dariusz Hiczkiewicz ${ }^{4}$, \\ Wojciech Homenda ${ }^{3}$, Dariusz Kozłowski ${ }^{3}$ \\ ${ }^{1}$ Department of Cardiology and Heart Electrotherapy, Medical University of Gdańsk \\ ${ }^{2}$ Cardiology Clinic of the Zdrowy Profil, Medical Center in Gdańsk \\ ${ }^{3}$ Institute of Health Sciences of the Pomeranian University in Słupsk \\ ${ }^{4}$ Clinical Department of Cardiology, Collegium Medicum, University of Zielona Góra
}

\begin{abstract}
Reflex syncope is among the most commonly encountered in the clinical practice. Most of these events are mild and do not require major therapeutic interventions. The major problem is recurrent syncope with injuries and a short prodromal symptom phase, usually related to a significant cardiodepressive response. One treatment method is implantation of a cardiac pacemaker. The aim of this article is to present the current knowledge on this subject.
\end{abstract}

Key words: vasovagal syncope, cardiac pacing

Folia Cardiologica 2021; 16, 6: 416-419

\section{Introduction}

Syncope is a transient loss of consciousness due to hypoperfusion of the central nervous system. Syncope is typically characterized by an abrupt onset, short duration, and spontaneous and complete return of consciousness. Syncope may be categorized into reflex, orthostatic and cardiogenic [1]. The category of reflex syncope includes the most commonly occurring vasovagal syncope (VVS). Depending on the dominant response of the cardiovascular system, VVS may be further subcategorized into the cardiodepressive (with bradycardia $<40$ beats per minute or asystole $>3 \mathrm{~s}$ ), vasodepressive (with hypotension without significant slowing of the sinus rhythm), and mixed type [2].

In a large majority of cases, VVS is mild and does not require any intervention except for non-pharmacological management (informing and educating about the triggers, recognition of prodromal symptoms, and maneuvers to avoid loss of consciousness) [1]. Novel methods are also used to improve autonomic nervous system regulation, including tilt training and heart rate variability (HRV) training by biofeedback, which may aid non-pharmacological management [3, 4]. A major problem is "severe syncope" - frequent and recurring episodes, particularly with a short prodromal phase. These events are associated with a risk of injury, and significantly impair the quality of life of the patients, interfering with their school, professional and social activities. Currently, no universal therapy is available that would be effective in all forms of reflex syncope. The 2018 European Society of Cardiology (ESC) guidelines recommend isometric exercise (class I), orthostatic training (class Ilb), drug therapy (with midodrine and fludrocortisone - class llb), and cardiac pacing (class Ila/llb) [1]. Cardiac pacing may be expected to be effective in patients with a predominant cardiodepressive component of VVS by preventing severe bradycardia or asystole. The present article summarizes the results of the studies on cardiac pacing in patients with reflex syncope.

Address for correspondence: Prof. Dariusz Kozłowski MD, PhD, Zakład Ratownictwa Medycznego, Katedra Pielęgniarstwa i Ratownictwa Medycznego, Instytut Nauk o Zdrowiu, Akademia Pomorska w Słupsku, ul. Arciszewskiego 22a, 76-200 Słupsk, Poland, e-mail: dkozl@gumed.edu.pl 


\section{Role of cardiac pacing in vasovagal syncope}

When selecting patients with reflex syncope for cardiac pacing, one should take into account the complex nature of the vasovagal reflex; the result of tilt testing does not always reflect actual syncopal events occurring in the patient's life [5]. This is particularly true with the most commonly used testing approach using nitroglycerin, often provoking prolonged asystole which may not necessarily occur during actual syncopal events in a given patient. In addition, syncopal events with vasodepressive and cardiodepressive components of varying severity may occur in the same patient, depending on specific circumstances and the patient's age $[6,7]$. It was also shown that changes in heart rate and blood pressure do not occur simultaneously. Loss of consciousness may result from hypotension even before asystole occurs [8]. In such circumstances, syncope may continue to occur despite pacemaker implantation.

On the other hand, early initiation of pacing with the provision of appropriately rapid heart rate may help maintain normal cardiac output and prolong the prodromal phase, which gives the patient time to assume a safer body position to prevent syncope and related injuries $[9,10]$. Another argument for pacing in VVS, particularly among patients above 60 years of age, is frequent concomitant presence of automaticity and conduction disorders within the sinoatrial node $[11,12]$.

Studies to prove the efficacy of implanted cardiac pacemakers in the management of VVS have been undertaken for many years. Initially, similarly to the management of paroxysmal third degree atrioventricular block, VVI pacing [13] followed by DDD pacing [14] was used. However, this therapy had no effect on the rate of syncopal events, while leading to a worsening of the quality of life in some patients (periods of inappropriate pacing, lack of atrioventricular synchrony, episodes of pacemaker-mediated tachycardia). The next step was the introduction of DDI pacing followed by hysteresis (initially negative, and then the search/scan hysteresis) [2, 15-17].

Based on the results of these studies, the rate drop response (RDR) algorithm was developed whereby sudden drop in the heart rate during VVS triggered a sequential atrioventricular pacing with a rate much higher compared to the basic pacing rate $[18,19]$. The initial data were very promising. In the North American Vasovagal Pacemaker Study (VPS) I study, patients with at least 3 syncopal episodes and a positive tilt test result were randomized to dual-chamber pacing with the RDR algorithm or no pacing. In the pacing group, a reduction in the syncope rate by 85\% was observed (confidence interval [CI] 59.7-94.7\%, $p=0.00002$ ) but the placebo effect of pacemaker implantation itself could not be excluded [10]. The latter issue was evaluated in the VPS II study. In this multi-center, randomized, double-blind trial, 100 patients with VVS had a dual chamber pacemaker implanted. The patients were then randomized to "active" pacing (DDD pacing with the RDR algorithm) or to the "inactive" stimulation (ODO stimulation, i.e. completely deactivated stimulation). Among 52 patients randomized to the ODO group, recurrent syncope at 6 months was noted in 22 (42\%), compared to $16(33 \%)$ of 48 patients in the DDD group. DDD pacing was found to be associated with a $30 \%$ reduction in the risk of syncope $(95 \% \mathrm{Cl}$ from $-33 \%$ to $63 \%$; one-sided $\mathrm{p}=0.14$ ) but the effect was not statistically significant [9]. Similar results were obtained in the Vasovagal Syncope and Pacing Trial (SYNPACE) [20].

Another randomized, placebo-controlled, double-blind trial was the Third International Study on Syncope of Uncertain Etiology (ISSUE 3). It included patients at least 40 years of age (mean age 63 years) with at least 3 syncopal events over 2 years, in whom syncope was associated with asystole lasting at least 3 seconds, or asymptomatic asystole lasting more than 6 seconds was documented by an implantable loop recorder (ILR). The patients were randomized to DDD pacing with the RDR algorithm or rhythm monitoring only. The rate of recurrent syncope at 2 years was $57 \%(95 \% \mathrm{Cl} 40-74)$ in the no pacing group compared to $25 \%(95 \% \mathrm{Cl} 13-45)$ in the active treatment group (reduction by $57 \%, p=0.039$ ) [21].

Of note, with the RDR algorithm, pacing is initiated only in response to a drop in the heart rate, when the vasovagal reaction is already well underway (in VVS, bradycardia is usually preceded by hypotension and a fall in cardiac output). This may be one reason why pacing does not always prevent syncope.

Another evaluated approach to pacing in patients with VVS was the closed loop stimulation (CLS) algorithm. In this method, measurement of intracardiac impedance serves as an indirect indicator of right ventricular contractility. Based on the measured value, pacing is initiated and its rate adjusted so as to prevent the vasovagal reaction at its early stage (before development of bradycardia or asystole). In the Inotropy Controlled Pacing in Vasovagal Syncope (INVASY) study, patients with recurrent syncope of the cardiodepressive type were randomized to DDD-CLS or DDI pacing. A recurrent syncopal event occurred in 7 of 9 patients in the DDI group, compared to none of 41 patients in the DDD-CLS group [22]. Similar results were obtained in the Closed Loop Stimulation for Neuromediated Syncope (SPAIN) study. It was a randomized, double blind, crossover trial that included patients at least 40 years of age with a history of frequent syncope ( $\geq 5$ episodes, or $\geq 2$ episodes during the last 12 months) and a cardiodepressive reaction confirmed during the tilt test. An at least 50\% reduction in the number of syncopal events was found in $72 \%$ (95\% Cl 47-90\%) 
of patients in the DDD-CLS group compared to $28 \%$ (95\% $\mathrm{Cl}$ 9.7-53.5\%) of patients in the DDI group ( $p=0.017$ ) [23]. In a metaanalysis that compared conventional pacing with CLS-based pacing in patients with recurrent VVS (6 studies, 224 patients), a clear superiority of CLSbased pacing was shown [24]. Similar results were obtained when CLS-based pacing was compared with RDR-based pacing (a meta-analysis of 5 studies, $n=228$ ) [25].

\section{Conclusions}

The proven efficacy of pacing does not mean it is always necessary. According to the 2018 ESC guidelines on the management of syncope [1], this therapy should be limited to a highly selected group of patients with severe reflex syncope. These are mostly older patients with recurrent loss of consciousness, short prodromal phase, and a high risk of injuries. The guidelines also noted that pacing should not be used (a class III recommendation) if the cardiodepressive mechanism of syncope was not shown. A class Ila recommendation was given for patients above 40 years of age with spontaneous symptomatic pause lasting more than 3 seconds or an asymptomatic one lasting more than 6 seconds. Pacing may also be considered in patients above 40 years of age with frequent abrupt syncopal event and asystole documented during the tilt test (a class IIb recommendation).

However, both these indications have a class I A recommendation in the most recent 2021 ESC guidelines on cardiac pacing [26]. This change is related to new studies on patients with asystole during the tilt test that were published since the publication of the previous guidelines. It was found that patients with at least 2 syncopal events per year and a pause lasting more than 3 seconds documented during the tilt test responded well to DDD pacing during reflex syncopal episodes. Thus, the tilt test was found to be useful not only for the diagnosis but also when selecting patients for this therapy. Patients with spontaneous asystole due to the vasovagal reflex (functional or adenosine-sensitive) were also given a class I recommendation for pacemaker implantation. Asystole during syncope induced during the tilt-test was also considered a class I recommendation, while a class Ilb recommendation was retained for adenosine-induced asystole. Of note, despite these changes in the level of recommendation, available data are insufficient to recommend pacemaker implantation in individuals below 40 years of age, and thus no such recommendation was given in the guideline document. In younger patients with predominantly cardiodepressive VVS, a possibility of lead-and pacemaker-related late long-term complications should be always taken in account. In these patients, cardioneuroablation (CNA) may be an alternative treatment approach. Initial reports on CNA in VVS showed a relevant reduction in frequency or even complete elimination of syncopal events. However, this method requires further studies [27].

\section{References}

1. Brignole M, Moya A, de Lange F, et al. 2018 ESC Guidelines for the diagnosis and management of syncope. Eur Heart J. 2018; 39(21): 1883-1948, doi: 10.1093/eurheartj/ehy037.

2. Petersen ME, Chamberlain-Webber R, Fitzpatrick AP, et al. Permanent pacing for cardioinhibitory malignant vasovagal syndrome. Br Heart J. 1994; 71(3): 274-281, doi: 10.1136/hrt.71.3.274, indexed in Pubmed: 8142198.

3. Ector H, Reybrouck T, Heidbüchel H, et al. Tilt training: a new treatment for recurrent neurocardiogenic syncope and severe orthostatic intolerance. Pacing Clin Electrophysiol. 1998; 21(1 Pt 2): 193-196, doi: 10.1111/j.1540-8159.1998.tb01087.x, indexed in Pubmed: 9474671.

4. Lehrer PM, Vaschillo E, Vaschillo B, et al. Heart rate variability biofeedback increases baroreflex gain and peak expiratory flow. Psychosom Med. 2003; 65(5): 796-805, doi: 10.1097/01. psy.0000089200.81962.19, indexed in Pubmed: 14508023.

5. Brignole M, Sutton R, Menozzi C, et al. International Study on Syncope of Uncertain Etiology 2 (ISSUE 2) Group. Lack of correlation between the responses to tilt testing and adenosine triphosphate test and the mechanism of spontaneous neurally mediated syncope. Eur Heart J. 2006; 27(18): 2232-2239, doi: 10.1093/eurheartj/ehl164, indexed in Pubmed: 16864606.

6. Olshansky B. Vasovagal syncope: to pace or not to pace. J Am Coll Cardiol. 2017; 70(14): 1729-1731, doi: 10.1016/j.jacc.2017.08.025, indexed in Pubmed: 28958329.

7. Sutton R, de Jong JSY, Stewart JM, et al. Pacing in vasovagal syncope: physiology, pacemaker sensors, and recent clinical trials - precise patient selection and measurable benefit. Heart Rhythm. 2020; 17(5 Pt A): 821-828, doi: 10.1016/j.hrthm.2020.01.029, indexed in Pubmed: 32036025.

8. Saal DP, Thijs RD, van Zwet EW, et al. Temporal relationship of asystole to onset of transient loss of consciousness in tilt-induced reflex syncope. JACC Clin Electrophysiol. 2017; 3(13): 1592-1598, doi: 10.1016/j.jacep.2017.07.006, indexed in Pubmed: 29759842.

9. Connolly SJ, Sheldon R, Thorpe KE, et al. VPS II Investigators. Pacemaker therapy for prevention of syncope in patients with recurrent severe vasovagal syncope: Second Vasovagal Pacemaker Study (VPS II): a randomized trial. JAMA. 2003; 289(17): 2224-2229, doi: 10.1001/ /jama.289.17.2224, indexed in Pubmed: 12734133.

10. Connolly SJ, Sheldon R, Roberts RS, et al. The North American Vasovagal Pacemaker Study (VPS). A randomized trial of permanent cardiac pacing for the prevention of vasovagal syncope. J Am Coll Cardiol. 1999; 33(1): 16-20, doi: 10.1016/s0735-1097(98)00549-x, indexed in Pubmed: 9935002.

11. Graff B, Graff G, Koźluk E, et al. Electrophysiological features in patients with sinus node dysfunction and vasovagal syncope. Arch Med Sci. 2011; 7(6): 963-970, doi: 10.5114/aoms.2011.26607, indexed in Pubmed: 22328878.

12. Budrejko S, Kempa M, Chmielecka M, et al. Analysis of heart rate variability during head-up tilt-test in patients with vasovagal syncope. Eur J Transl Clin Med. 2018; 1(1): 24-36, doi: 10.31373/ejtcm/92837.

13. Kus $\mathrm{T}$, Lalonde $\mathrm{G}$, Champlain $\mathrm{D}$, et al. Vasovagal syncope: management with atrioventricular sequential pacing and beta-blockade. Can J Cardiol. 1989; 5: 375-378, indexed in Pubmed: 2575013. 
14. McGuinn WP, Wilkoff B, Maloney J, et al. Treatment of autonomically-mediated syncope with rapid AV sequential pacing on demand. J Am Coll Cardiol. 1991; 17(2): A271, doi: 10.1016/0735-1097(91)92051-m.

15. Fitzpatrick AP, Theodorakis G, Ahmed R, et al. Dual chamber pacing aborts vasovagal syncope induced by head-up 60 degree tilt. PACE. 1991; 14: 13-19.

16. Sra JS, Jazayeri MR, Avitall B, et al. Comparison of cardiac pacing with drug therapy in the treatment of neurocardiogenic (vasovagal) syncope with bradycardia or asystole. N Engl J Med. 1993; 328(15): 1085-1090, doi: 10.1056/NEJM199304153281504, indexed in Pubmed: 8455666.

17. Sutton R, Brignole M, Menozzi $\mathrm{C}$, et al. Dual-chamber pacing in the treatment of neurally mediated tilt-positive cardioinhibitory syncope: pacemaker versus no therapy: a multicenter randomized study. The Vasovagal Syncope International Study (VASIS) Investigators. Circulation. 2000; 102(3): 294-299, doi: 10.1161/01.cir.102.3.294, indexed in Pubmed: 10899092.

18. Benditt DG, Sutton R, Gammage M, et al. "Rate-drop response" cardiac pacing for vasovagal syncope. J Interv Card Electrophysiol. 1999; 3(1): 27-33, doi: 10.1023/a:1009815304770, indexed in Pubmed: 10354973.

19. Benditt DG, Sutton R, Gammage MD, et al. Clinical experience with Thera DR rate-drop response pacing algorithm in carotid sinus syndrome and vasovagal syncope. The International Rate-Drop Investigators Group. Pacing Clin Electrophysiol. 1997; 20(3 Pt 2): 832-839, doi: 10.1111/j.1540-8159.1997.tb03916.x, indexed in Pubmed: 9080522.

20. Raviele A, Giada F, Menozzi C, et al. Vasovagal Syncope and Pacing Trial Investigators. A randomized, double-blind, placebo-controlled study of permanent cardiac pacing for the treatment of recurrent tilt-induced vasovagal syncope. The vasovagal syncope and pacing trial (SYNPACE). Eur Heart J. 2004; 25(19): 1741-1748, doi: 10.1016/ /j.ehj.2004.06.031, indexed in Pubmed: 15451153.
21. Brignole M, Menozzi C, Moya A, et al. International Study on Syncope of Uncertain Etiology 3 (ISSUE-3) Investigators. Pacemaker therapy in patients with neurally mediated syncope and documented asystole: Third International Study on Syncope of Uncertain Etiology (ISSUE-3): a randomized trial. Circulation. 2012; 125(21): 2566-2571, doi: 10.1161/CIRCULATIONAHA.111.082313, indexed in Pubmed: 22565936.

22. Occhetta E, Bortnik M, Audoglio R, et al. INVASY Study Investigators. Closed loop stimulation in prevention of vasovagal syncope. Inotropy Controlled Pacing in Vasovagal Syncope (INVASY): a multicentre randomized, single blind, controlled study. Europace. 2004; 6(6): 538-547, doi: 10.1016/j.eupc.2004.08.009, indexed in Pubmed: 15519257.

23. Baron-Esquivias G, Morillo CA, Moya-Mitjans A, et al. Dual-chamber pacing with closed loop stimulation in recurrent reflex vasovagal syncope: the SPAIN study. J Am Coll Cardiol. 2017; 70(14): 1720-1728, doi: 10.1016/j.jacc.2017.08.026, indexed in Pubmed: 28958328.

24. Rattanawong P, Riangwiwat T, Chongsathidkiet P, et al. Closed-looped stimulation cardiac pacing for recurrent vasovagal syncope: a systematic review and meta-analysis. J Arrhythm. 2018; 34(5): 556-564, doi: 10.1002/joa3.12102, indexed in Pubmed: 30327702.

25. da Cunha GJ, Rocha BM, Gomes RV, et al. A systematic review on recurrent cardioinhibitory vasovagal syncope: does pacing therapy break the fall? Pacing Clin Electrophysiol. 2019; 42(10): 1400-1407, doi: 10.1111/pace.13790, indexed in Pubmed: 31433493.

26. Glikson M, Cosedis Nielsen J, Kronborg MB, et al. ESC Scientific Document Group. 2021 ESC Guidelines on cardiac pacing and cardiac resynchronization therapy . Eur Heart J. 2021; 42(35): 3427-3520, doi: 10.1093/eurheartj/ehab364, indexed in Pubmed: 34455430.

27. Garcia A, Marquez MF, Fierro EF, et al. Cardioinhibitory syncope: from pathophysiology to treatment-should we think on cardioneuroablation? J Interv Card Electrophysiol. 2020; 59(2): 441-461, doi: 10.1007/s10840-020-00758-2, indexed in Pubmed: 32377918. 